
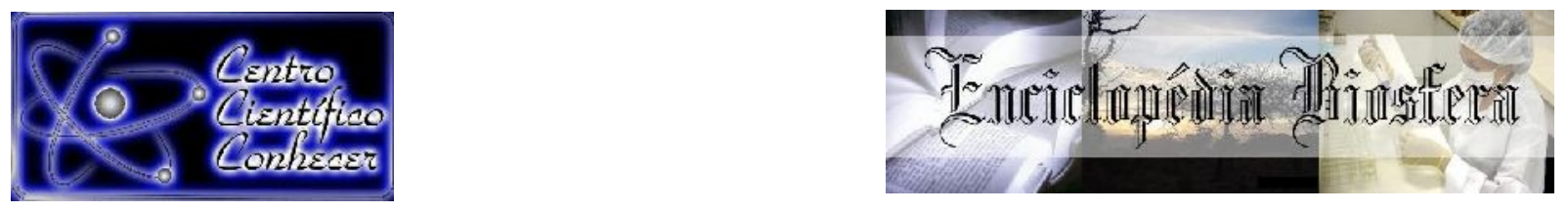

\title{
BEM-ESTAR E MANEJO PRÉ-ABATE E SUAS INFLUÊNCIAS SOBRE A QUALIDADE DE CARNE E CARCAÇA DE BOVINOS DE CORTE
}

\author{
Luis Gustavo Castro Alves ${ }^{1}$, Alexandre Rodrigo Mendes Fernandes ${ }^{2}$, Giancarlo de \\ Moura Souza ${ }^{3}$, Camila Magalhães da Cunha ${ }^{4}$, Luciana Foppa ${ }^{5}$
}

${ }^{1}$ Doutor em Ciência Animal pela Universidade Estadual de Londrina - UEL, Londrina PR, Brasil. Email - gustavo353@hotmail.com. Trabalho de Conclusão de Curso na Especialização em Higiene e Inspeção de Produtos de Origem Animal pela UNYLEYA;

${ }^{2}$ Docente na Faculdade de Ciências Agrárias da Universidade Federal da Grande de Dourados - UFGD, Dourados - MS, Brasil;

${ }^{3}$ Doutor em Ciência Animal e Pastagens, Universidade de São Paulo - USP, São Paulo - SP, Brasil;

${ }^{4}$ Mestre em Zootecnia pela Universidade Federal da Grande de Dourados - UFGD, Dourados - MS, Brasil;

${ }^{5}$ Doutoranda em Ciência Animal pela Universidade Estadual de Londrina - UEL, Londrina - PR, Brasil.

\section{Recebido em: 06/04/2019 - Aprovado em: 10/06/2019 - Publicado em: 30/06/2019 DOI: 10.18677/EnciBio_2019A200}

\begin{abstract}
RESUMO
A cadeia produtiva da carne bovina tem evoluído nos últimos anos em direção à diferenciação de produtos de qualidade. Os atuais sistemas de produção ofertam produtos diferenciados, demandando animais de qualidade e remuneração aos produtores. Problemas de manejo e logísticas podem prejudicar a cadeia produtiva, gerando perdas de qualidade econômicas no produto final. As contusões nas carcaças representam as principais perdas no frigorífico, pois, ocasionam quedas de rendimento de carcaça, danos aos cortes comerciais, como o traseiro, lombo e a ponta de agulha e consequentemente diminuição da qualidade da carcaça. Ocasionadas no animal, as contusões são reflexo de problemas durante o manejo pré-abate, nas instalações e/ou das características dos animais. A mensuração é possível somente apenas após abate com a retirada do couro, tornando difícil caracterizá-las no momento em que ocorrem as lesões. Objetivou-se determinar os principais agentes causadores das contusões em carcaças bovinas desde o embarque na propriedade até o abate no frigorífico e as consequências na qualidade da carcaça e da carne. As soluções devem estar embasadas em leis e normativas mais rigorosas entre os órgãos governamentais e instituições, aliadas também ao pecuarista e indústria, seguidas das adequadas etapas pré-abate para que possam entregar, dessa forma, produto idôneo aos consumidores.
\end{abstract}

PALAVRAS -CHAVE: contusão, distâncias, perdas no produto final 


\title{
ANIMAL WELFARE AND PRE SLAUGHTER MANAGEMENT AND THEIR INFLUENCES ON THE QUALITY OF CATTLE MEAT AND CARCASSES
}

\begin{abstract}
The beef production chain has evolved, in recent years towards, the differentiation of quality products. The current production systems offer differentiated products, demanding quality. Management and logistic problems can damage the productive chain, generating losses, of quality and economic, in the final product. In this sense, the carcass contusions represent the main losses for the slaughterhouse, once there is a drop in carcass yield, damage to the commercial cuts, rear, loin, and needle point and consequently a decrease in the quality of the carcass. These injuries affect the living animal and they are a reflection of problems during pre-slaughter handling, on the premises and/or on the characteristics of the animals. Measurement is possible only after slaughter with removal of the leather, making it difficult to characterize them at the time of injury. The aim of the present study was to determine the main agents that cause bruises in bovine carcasses from loading on the farm to slaughtering in the slaughterhouse and the consequences on the quality of carcass and meat. Solutions must certainly be based on more stringent laws and regulations between government agencies and institutions, allied to the producers and industry, followed by appropriate pre-slaughter steps so that they can deliver a product suitable for consumers.
\end{abstract}

KEYWORDS: contusion, distances, losses of final product

\section{INTRODUÇÃO}

O bem-estar animal é, em partes, resultado da associação das ações voltadas ao manejo pré-abate, sendo responsabilidade conjunta de proprietários, funcionários e articuladores de negociações. Neste contexto, negligenciar alguma dessas etapas pode resultar tanto no aumento dos níveis de estresse, bem como em dor ou ferimentos oriundos da falta de conhecimentos a respeito da biologia e comportamento dos animais. Nos últimos anos, o mercado consumidor evoca que se respeite o bem-estar dos animais de produção, pelo anseio de alimentos que sejam seguros e produzidos de forma sustentável (SILVA; BORGES, 2015).

Desta forma, é crescente a conscientização dos diversos elos da cadeia de produção de proteína animal, direcionadas às áreas de nutrição, melhoramento genético e reprodução aliados aos parâmetros de bem-estar animal (BARBUT, 2014; ALVES et al., 2016).

Há algumas décadas, o processo de pré-abate dos animais era considerado uma operação tecnológica de baixo nível científico e não se constituía em tema pesquisado com afinco. Entretanto, atualmente, tem-se atribuído grande importância ao tema em decorrência das perdas econômicas decorrentes do manejo ineficaz, atraindo cada vez mais a atenção de setores de pesquisa para o estudo de métodos que possam identificar fatores geradores de prejuízos para cadeia produtiva da carne (GUERRERO et al., 2013).

Uma vez que a remuneração paga aos produtores é realizada de acordo com o peso das carcaças, mensurado ao final da linha de abate, após a toalete, evisceração, divisão da carcaça e retirada de todas as lesões e alterações que apresentarem ao 
longo da sua inspeção, independentemente de sua localização. Logo, à medida que precisam ser removidas as lesões na linha de abate, essas acabam por depreciar os cortes atingidos, podendo muitas vezes, comprometer até mesmo a qualidade do couro, coproduto de alto valor agregado na cadeia produtiva (MOREIRA et al., 2017).

As contusões em bovinos são frequentes durante o processo, porém cabe à pesquisa e a indústrias estudarem formas de mitigá-las, além de determinar os principais pontos causadores, evitando assim, perdas econômicas, assegurando produtos com maior qualidade (GOMIDE et al., 2014; MPAKAMA, et al., 2014). Diante do exposto, o objetivo do presente estudo foi identificar os principais agentes causadores das contusões em carcaças bovinas desde o embarque na propriedade até o abate no frigorífico e suas possíveis consequências na qualidade da carcaça e da carne.

\section{DESENVOLVIMENTO}

Durante o manejo pré-abate, de acordo com Mendonça et al. (2016), os animais podem ser expostos a desafios que perturbam sua homeostase, portanto, deverão ser considerados todos os atributos que interfiram nesta fase:

\section{Capacitação da mão de obra}

Os resultados obtidos desde a propriedade até o processamento do produto final dependem diretamente da eficiência da mão de obra. Portanto, quantificar e mensurar o grau de conhecimento, seja com cursos de capacitação, destes indivíduos que trabalham em cada segmento é fundamental para cadeia da carne bovina.

Destaca-se a utilização incorreta de instrumentos de manejo, de forma que agridam os animais, aumentem as variações de reatividade animal, agressões diretas e quedas, fatores primordiais para o aumento no estresse dos animais e do número de contusões e hematomas (GONÇALVES et al., 2017). Mendonça et al. (2016) observaram associação de tais instrumentos aversivos utilizados no manejo de embarque com a frequência de contusões graves nas carcaças. As consequências relacionadas ao manejo de embarque e desembarque, representam maiores riscos de contusões para os animais do que a distância percorrida na viagem.

Neste contexto, Grandin (2014) afirma que a redução do uso do bastão elétrico melhora o bem-estar animal durante o manejo. De acordo com Ludtke et al. (2015), o bastão deve ser utilizado apenas como último recurso para movimentar o animal, somente na região posterior, acima do jarrete, e desde que não ultrapasse um segundo e o animal tenha espaço para avançar. O percentual de utilização é atribuído em relação ao bovino que recebeu o choque (presença ou ausência) e não ao número de choques recebidos. Qualquer resultado maior que $25 \%$ é inaceitável, independente do volume de abate, sendo considerado um resultado excelente se $5 \%$ ou menos dos animais receberem choques.

A vocalização é emitida pelo bovino em resposta a algum estímulo aversivo (fator estressante), ou seja, um indicador de desconforto durante o manejo, contenção e insensibilização. A amostragem para este atributo deve ser de $50 \%$ dos animais na saída dos currais até o brete e $50 \%$ no boxe de insensibilização. O percentual é atribuído em relação ao bovino que vocalizou e não pela quantidade de vocalizações. 
Para a coleta de dados, um único animal que vocaliza mais de uma vez durante o manejo pré-abate deve ser pontuado apenas uma vez. É considerado um resultado excelente se até $1 \%$ dos bovinos vocalizarem, aceitável até 3\%, não aceitável de $4 \%$ a $10 \%$, e sérios problemas quando há vocalização de mais de $10 \%$ dos animais (LUDTKE et al., 2015).

\section{Comportamento dos animais durante o manejo}

Dentre as características de comportamento animal mais estudadas nos últimos anos, está o temperamento. Essa característica pode ser definida como a resposta comportamental dos animais às ações humanas durante a rotina de manejo, geralmente como reflexo do sentimento de medo (PEIXOTO et al., 2011). Portanto, é um estado emocional indesejável, visto que reduz o bem-estar dos animais e sinaliza técnicas de manejo ineficientes.

Embora, seja um traço intrínseco de cada animal, o temperamento pode ter reflexos econômicos, uma vez que pode implicar, dentre outros fatores, no aumento efetivo de funcionários capacitados, em riscos com relação à segurança dos trabalhadores e em perda de rendimento e de qualidade da carne, oriundos de contusões e estresse durante o manejo pré-abate. Por conseguinte, o conhecimento e a compreensão do comportamento animal são de extrema importância para a realização de um manejo eficiente e adequado, capaz de mitigar ou evitar tais situações (GRANDIN, 2014).

O bem-estar animal também pode ser afetado pela espécie, raça, linhagem genética e pela categoria, idade, tamanho corporal, condições anatômicas e grau de acabamento (GONZÁLEZ et al., 2012; OIE, 2014).

Bovinos são animais sociais e devem ser conduzidos sempre em grupo. Dentro do grupo, os bovinos estabelecem uma hierarquia de dominância imposta por competição. Todavia, ao serem separados ou isolados, os animais tendem a tornaremse mais agitados e agressivos. Em situações de mistura de animais desconhecidos, há o estabelecimento de uma nova hierarquia, geralmente com comportamentos agressivos e referentes à luta. Por essa razão, lotes de bovinos transportados para o frigorífico devem, preferencialmente, conter animais familiarizados, evitando-se misturar animais desconhecidos (LUDTKE et al., 2015).

Paranhos da Costa et al. (2012) ressaltaram que a liderança é outro aspecto, cuja compreensão pode ser útil na condução do rebanho por auxiliar na sincronia de comportamento dos bovinos. A caracterização do reportório comportamento dos bovinos deve estar atrelada a suas características sensoriais, como visão, olfato e audição. Os bovinos dependem principalmente desses sentidos, para avaliar estímulos e assim responder a diferentes situações, como mudanças no ambiente e ameaças (LUDTKE et al., 2015). A comunicação através do olfato, por exemplo, pode ocorrer em situações de tensão pela liberação de feromônios através da urina e saliva, alertando outros bovinos sobre a situação estressante em que se encontram.

O estudo do campo visual dos bovinos é de grande importância durante o manejo dos animais, sendo determinantes para a definição do posicionamento do técnico responsável pela condução dos bovinos. Grandin (2014) sugere que o movimento dos animais será facilitado se as pessoas envolvidas conhecerem os 
conceitos de zona de fuga e ponto de equilíbrio. Ludkte et al. (2015) relatam que o princípio do ponto de equilíbrio é bastante utilizado em corredores estreitos ou bretes, nos quais a movimentação dos animais é limitada, podendo apenas avançar ou recuar (Figura 1).

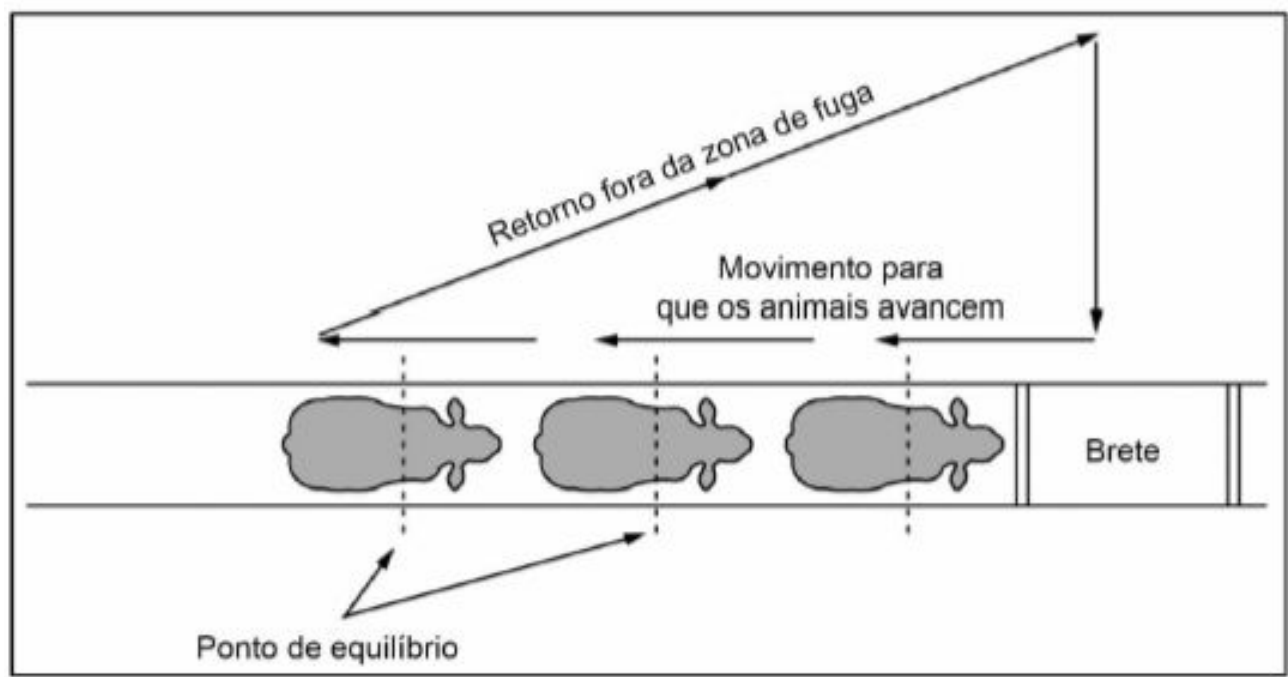

FIGURA 1 - Padrão de movimento para induzir o gado a avançar. Fonte Adaptado Grandin (2014).

Andar rapidamente após o ponto de equilíbrio do animal, no sentido oposto ao movimento desejado, é uma maneira fácil de induzir um animal a avançar. O princípio é andar dentro da zona de fuga, na direção oposta do movimento desejado e por fora da zona de fuga para retornar à posição inicial. O manejo de bovinos deve ser tranquilo, sem barulho, gritos, correria ou movimentos bruscos, além disso, deve-se evitar objetos pontiagudos ou de condução elétrica. Os animais devem estar atentos ao comando do manejador, ao passo que agitação excessiva pode causar pânico e descontrole (GRANDIN, 2014).

\section{Bem-estar durante o transporte}

No Brasil, a maioria dos animais destinados ao abate é transportada em caminhões por rodovias. As redes de rodovias brasileiras possuem mais de 1,6 milhões de quilômetros, sendo 1,3 milhões $\mathrm{km}$ de rodovias municipais, $230.000 \mathrm{~km}$ de rodovias estaduais e $73.000 \mathrm{~km}$ de rodovias federais. Apenas 12,4\% das rodovias federais são pavimentadas. Segundo a Confederação Nacional do Transporte (CNT, 2018), 61,8\% das estradas apresentam algum tipo de problema, sendo classificadas como regular, ruim ou péssima. Já a sinalização e a geometria da via têm classificação regular, ruim ou péssima, com índices de $59,2 \%$ e de $77,9 \%$, respectivamente.

Neste contexto, a condução dos bovinos, da propriedade até o frigorífico, é uma etapa do pré-abate importante, pois muitos fatores como tipo de veículo, densidade, distância, tempo percorrido, condições das estradas, motorista, temperatura, além da associação de dois ou mais destes fatores, são determinantes e causadores de estresse nos animais e contusões nas carcaças, edemas, quedas de $\mathrm{pH}$, alterações na 
coloração, maciez e qualidade da carne (ROMERO et al., 2013; MENDONÇA, et al., 2017).

Broom (2005) sugere que a seleção de um veículo apropriado é importante para o bem-estar animal, visto que as condições físicas dentro dos veículos podem afetar o grau de estresse dos animais. Veículos com as laterais do compartimento de carga completamente fechadas podem oferecer vantagem na redução do estresse dos animais, pois o fechamento limita os estímulos externos e reduz a agitação dos animais, mas também pode reduzir a ventilação, fato que se agrava quando o veículo está parado (PARANHOS DA COSTA, 2012). Assim, considerando que as condições físicas do ambiente, como temperatura e umidade, podem mudar durante a viagem, é importante que o responsável pelos animais realize um monitoramento eficiente através de inspeções com frequência adequada (SILVA et al., 2016).

O principal aspecto a ser considerado durante o transporte de bovinos é o espaço ocupado por animal, ou seja, a densidade de carga. Alta densidade de carga em um veículo em movimento aumentam os riscos de ferimentos aos animais e danos a carcaça e qualidade da carne. Por sua vez, a densidade menores que a ideal, há maior risco de quedas devido à perda de equilíbrio (PARANHOS DA COSTA et al., 2010; SILVA et al., 2016). A densidade da carga pode ser classificada em alta $\left(600 \mathrm{Kg} / \mathrm{m}^{2}\right)$, média $\left(400 \mathrm{Kg} / \mathrm{m}^{2}\right)$ e baixa $\left(200 \mathrm{Kg} / \mathrm{m}^{2}\right)$, a ideal é, em média, 390 a $410 \mathrm{Kg} / \mathrm{m}^{2}$, não recomendadas densidades superiores a $550 \mathrm{Kg} / \mathrm{m}^{2}$ (DINIZ et al., 2011).

Por exemplo, para bovinos de $500 \mathrm{~kg}$, dividir o comprimento de cada compartimento por 0,51 , refere-se ao espaço linear m/animal para esse peso corporal. Para um caminhão truck, no primeiro compartimento com espaço de 2,45m/0,51m = 4,8 animais, adota como 4 animais, no segundo compartimento $5,51 \mathrm{~m} / 0,51 \mathrm{~m}=10,8$ animais, adota 10 animais, no terceiro compartimento com espaço de $2,35 \mathrm{~m} / 0,51 \mathrm{~m}=$ 4,6 animais, adota 4 animais. Portanto, esse veículo tem capacidade de transportar 18 animais de $500 \mathrm{~kg}$. Vale ressaltar, que o cálculo para determinar a densidade deve ser baseado dividindo o comprimento de cada compartimento do veículo pelo valor referente ao peso corporal do animal ou do lote (PARANHOS DA COSTA et al., 2010).

Outro ponto importante é o risco de escorregões e quedas durante o transporte dos animais, que pode ser evitado com boas condições de limpeza e conservação dos veículos. Os pisos dos compartimentos de carga devem ser cobertos com um tapete de borracha e, sobre esse, deve-se instalar uma grade de ferro quadriculada (com quadrados com aproximadamente $30 \mathrm{~cm}$ de largura) proporcionando conforto e segurança aos animais (PARANHOS DA COSTA et al., 2012).

A distância de transporte influencia significativamente o metabolismo post mortem de bovinos, aumentando o $\mathrm{pH}$ final e diminuindo o teor de lactato do músculo. Comparado à menores distâncias de percursos, o estresse causado pela maior distância de transporte em bovinos está associado ao aumento do tempo de jejum e do ácido lático no plasma, com consequente redução de sua concentração a nível muscular, nas 24 horas post mortem. O ideal é que os bovinos sejam abatidos em plantas frigoríficas localizadas o mais próximo possível das fazendas produtoras (FONSECA et al., 2014).

As longas jornadas sem água e alimento, às vezes com condições climáticas desfavoráveis, manejo inadequado e tempo de espera pré-abate longo são 
características observadas em muitos países, afetando o bem-estar e a qualidade da carne (LEITE et al., 2015). Além disso, outro ponto importante observado, é a perda de peso durante o transporte, afetando o bem-estar dos animais e causando perdas econômicas, principalmente devido à perda do conteúdo intestinal que corresponde a 12 a $25 \%$ do peso corporal do animal. A perda de peso tem razão direta com o tempo de transporte, variando de 4\% para jornadas de cinco horas a 7\% para jornada de 15 horas, perda essa que só é recuperada após cinco dias (GOMIDE et al., 2006).

Paranhos da Costa et al. (2012) identificaram os pontos perigosos e estressantes para os animais no transporte, e afirmaram que os riscos de injúrias e danos às carcaças estão ligados às condições das estradas, ao treinamento dos funcionários envolvidos e ao cuidado ao dirigir os caminhões. Nunes et al. (2018) ressaltam que traumatismos e contusões são bastante comuns no transporte de bovinos, devido à densidade inadequada, ao tipo de piso, à carroceria do veículo com defeitos, ao excesso de velocidade nas curvas, aceleração e freadas bruscas durante a viagem.

\section{Contusões: número, grau e local na carcaça}

As contusões são lesões teciduais sem laceração, usualmente produzidas por objetos que causam impacto superficial no animal com força necessária para romper os vasos e acumular sangue nos tecidos. As lesões não são vistas no animal vivo, devido à espessura e à característica da pele de bovinos, salientando a importância de sua detecção na inspeção no período post mortem (STRAPPINI et al., 2009). As contusões são definidas em graus de acordo com a sua profundidade, isto é, aos diferentes tecidos corporais atingidos. Aquelas de grau I afetam somente o tecido subcutâneo, as de grau II afetam também o tecido muscular e, por fim, as de grau III afetam os tecidos subcutâneo, muscular e ósseo (CIVEIRA et al., 2006).

Em estudo conduzido por Miranda-de La Lama et al. (2012), 92\% das carcaças analisadas (1143 animais) apresentaram algum tipo de lesão, e dessas, 23\% apresentaram diâmetro menor que $5 \mathrm{~cm}, 72 \%$ entre 6 a $10 \mathrm{~cm}$ e $5 \%$ maiores que $10 \mathrm{~cm}$ de diâmetro. Em termos de severidade, $68 \%$ foram consideradas de grau I, $30 \%$ de grau II e $2 \%$ de grau III. A alta incidência de lesões em carcaças é comumente observada em grandes plantas de abate que evidenciam sérios problemas de manejo dos animais durante o período pré-abate (FRASÃO et al., 2014).

Os resultados obtidos por Civeira et al. (2006), corroboram que a ocorrência de hematomas nas carcaças é indicativa de manejo racional que pode ter ocorrido em qualquer etapa do processo: na fazenda, durante o transporte, no desembarque e na planta frigorífica (Figura 2). É importante pontuar que hematomas também podem ocorrer após a insensibilização e antes da sangria. Assim, fica evidente que a ocorrência de hematomas é de origem multifatorial e de difícil diagnóstico (STRAPPINI et al., 2013). 

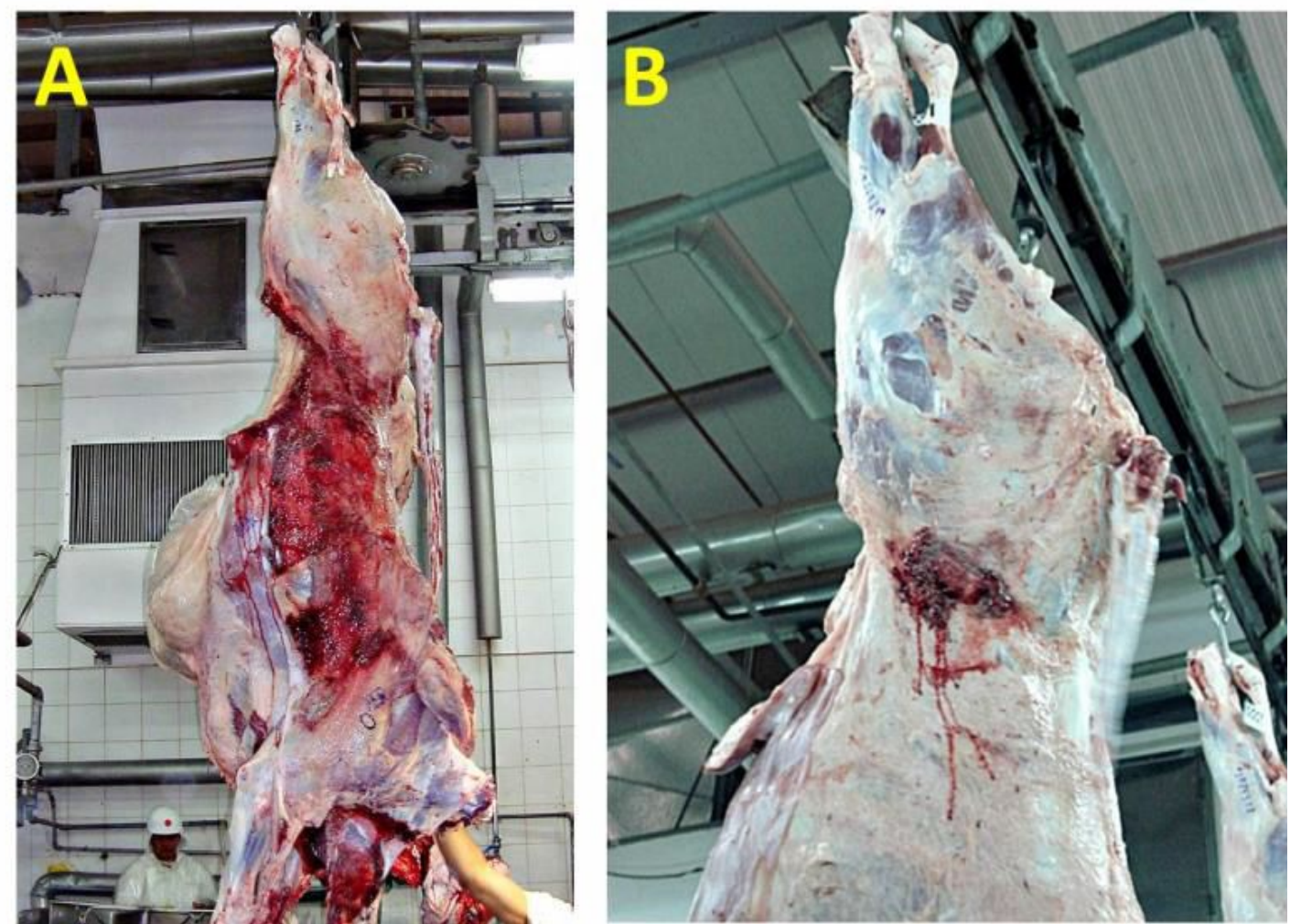

FIGURA 2 - Carcaças de bovinos com hematomas. A) hematoma originado pelo pisoteio, após a queda do animal durante o transporte e, (B) hematoma originado da colisão do animal com a porteira do caminhão durante a etapa de desembarque na planta frigorífica. Fonte: Pellecchia, (2014).

Portanto, as contusões não são apenas uma indicação da falta do bem-estar animal, mas também provocam significativas perdas econômicas diretas e indiretas. As perdas diretas estão relacionadas à perda de peso e desfiguração de cortes musculares e depreciação das carcaças (MELO et. al., 2016). Por sua vez, as indiretas estão relacionadas ao estresse, envolvendo a qualidade do produto, aos serviços executados para limpeza e a vida de prateleira do produto (MOREIRA et al., 2017).

Polizel Neto et al. (2015) avaliaram as perdas econômicas decorrentes de lesões de transporte e manejo pré-abate em carcaças de bovinos abatidos em Mato Grosso. Os animais lesionados apresentaram de uma até seis lesões em sua carcaça, com uma maioria, 96,9\%, variando entre 11 a quatro lesões, sendo que os animais transportados por mais de duas horas apresentaram mais lesões que os animais transportados por até duas horas. O local de maior incidência de lesões foi o lombo, com 50,35\% das lesões, seguido pela região do coxão com $36,38 \%$ das lesões encontradas neste estudo. Foi calculada uma perda no valor de $115,76 \mathrm{~kg}$ para o total de animais estudados, estima-se que para um frigorífico de médio porte, acumula-se uma perda anual superior a 200 mil reais com lesões em carcaças bovinas decorrentes do transporte e manejo pré-abate.

Nunes et al. (2018) avaliaram a incidência de hematomas em carcaças em bovinas submetidas ao transporte rodoviário. Observaram que animais que percorreram maiores distâncias até o frigorífico apresentaram maior número de lesões nas carcaças, 
sendo que, $97,81 \%$ das carcaças avaliadas, apresentaram um ou mais hematomas. Além disso, a região sacral e lombar foram as que obtiveram a maior percentagem média de hematomas, 31,77 e 31,63\%, respectivamente.

Esses autores acima, ressaltaram que hematomas na área posterior da carcaça podem representar maiores perdas econômicas pois cortes cárneos de maior valor agregado se localizam nessa área. Fêmeas e machos inteiros foram os grupos com maior número de carcaças com hematomas. As lesões representaram uma perda média de 0,225 kg por carcaça, gerando uma perda econômica média de $R \$ 2,14$, sendo que as fêmeas apresentaram maior perda por lesões quando comparadas a machos inteiros e castrados.

Mendonça et al. (2016) avaliaram o efeito da distância de transporte de animais para o frigorífico sobre a ocorrência de contusões nas carcaças e contabilizaram 13.110 contusões em diferentes regiões das carcaças. Além disso, foi observado que a incidência de contusões por animal aumentou gradativamente à medida que aumentou a distância do frigorífico a partir de $100 \mathrm{~km}$ (Tabela 1).

TABELA 1. Porcentagens e incidência de contusões nos cortes comerciais em relação à distância $(\mathrm{km})$

\begin{tabular}{ccccccc}
\hline Distância $(\mathrm{km})$ & Quadril & Traseiro & Costilhar & Dianteiro & Lombo & Incidência $^{1}$ \\
\hline <99 & 18,98 & 17,48 & 25,99 & 28,66 & 19,35 & 1,7 \\
100 a 199 & 14,75 & 12,73 & 15,83 & 15,77 & 18,18 & 1,2 \\
200 a 299 & 18,47 & 18,08 & 18,22 & 18,60 & 17,60 & 1,4 \\
300 a 399 & 21,89 & 22,74 & 16,49 & 14,44 & 16,62 & 1,5 \\
400> & 25,91 & 28,98 & 23,47 & 22,53 & 28,25 & 2,0 \\
\hline
\end{tabular}

${ }^{1}$ Contusões por animal ou número de contusões dividido por número de animais. Fonte: Mendonça et al. (2016).

Petroni et al. (2013) relataram média de 2,53 contusões por animal quando as distâncias percorridas são de até $200 \mathrm{~km}$, aumentando para 3,37 entre 200 e $400 \mathrm{~km}$ e 3,83 acima de $400 \mathrm{~km}$. Neste estudo, foi observada maior incidência de lesões nas carcaças observada até 100 km, não superando apenas distâncias maiores que 400 $\mathrm{km}$.

Resultados similares foram relatados por Mendonça et al. (2019), no qual a maior frequência de lesões foi obtida de animais provenientes da região geográfica e, que segundo os autores, podem estar associadas a alta participação de animais mestiços de raças zebuínas nessa região. A respeito da região da carcaça, foi verificado maior proporção de contusões de quadril, traseiro e lombo em animais transportados acima de $400 \mathrm{~km}$ e maior proporção de contusões de costilhar e dianteiro para distância abaixo de $100 \mathrm{~km}$.

Moreira et al. (2014) constataram que dos animais submetidos a distâncias superiores à $200 \mathrm{~km}$ estão mais sujeitos a sofrerem algum tipo de lesão, devido a fatores físicos e psicológicos promotores de estresse. Almeida et al. (2017) relataram a ocorrência de 0,24\% de carcaças condenadas parcialmente decorrentes de fraturas de fêmur. Sabe-se que os cortes mais valorizados se encontram no posterior do animal e, desta forma, o aumento de lesões nesta região aumenta o descarte e prejuízos econômicos. O manejo pré-abate interfere diretamente neste resultado, sendo assim, os ENCICLOPÉDIA BIOSFERA, Centro Científico Conhecer - Goiânia, v.16 n.29; p.403 2019 
cuidados nesta fase devem ser redobrados a fim de mitigar e até mesmo evitar as lesões nas carcaças.

\section{Efeitos na qualidade da carne}

O termo estresse se refere aos ajustes fisiológicos, tais como alterações no ritmo cardíaco e respiratório, temperatura corporal e pressão sanguínea, realizados pelo organismo, quando o animal é exposto a condições adversas (estressores). Todo estresse imposto ao animal na fase ante mortem irá desencadear reações que podem resultar em rigor mortis atípico e irão interferir diretamente na qualidade da carne. $O$ estresse aliado ao esforço físico realizado nas operações de embarque, transporte, desembarque e permanência em currais do frigorífico modificam o metabolismo post mortem, principalmente a velocidade de glicólise e o nível de acidez muscular (GOMIDE et al., 2014).

Neste contexto, Coutinho et al. (2017) avaliaram o efeito do temperamento de zebuínos sobre a atividade inibitória de calpastatina e identificaram a relação desses genótipos com a força de cisalhamento, no qual, animais mais reativos apresentaram maior dureza da carne e menor extensão de amaciamento nas 48 horas do período post-mortem. Neste contexto, Mendonça et al. (2017) observaram que fêmeas são mais susceptíveis às alterações no $\mathrm{pH}$ final das carcaças, principalmente quando a carcaça é proveniente de animais zebuínos.

Mesmo que o animal seja produzido dentro dos critérios de qualidade, a carne poderá ter a qualidade comprometida, caso não sejam respeitadas as boas práticas de manejo de abate (CRUZ-MONTERROSA et al., 2017). Esses cuidados devem ser criteriosamente cumpridos desde da condução dos animais da fazenda para envio ao frigorífico, até o momento da insensibilização na linha de abate (LUDTKE, et al., 2015).

O rigor mortis é um processo da conversão do músculo em carne, caracterizado pelo enrijecimento da musculatura. Este processo decorre da formação de ligações cruzadas permanentes entre os miofilamentos de actina e miosina, formando a actomiosina, decorrente de condições que impossibilitam a geração de ATP pela quase completa exaustão das reservas energéticas (glicogênio) e queda do pH (ROÇA, 2001). $\mathrm{O}$ rigor é dependente da temperatura, $\mathrm{pH}$ e quantidade de glicogênio presente na musculatura no pré-abate.

As mudanças físicas que acompanham o rigor mortis são perda de elasticidade e extensibilidade e o aumento de tensão. O parâmetro mais utilizado para acompanhar o fenômeno do rigor é a extensibilidade. Logo após a sangria, o músculo é extensível e elástico, pois nesse período existem poucas pontes actomiosina.

Logo, com a morte e consequente falência sanguínea, o aporte de oxigênio e o controle nervoso deixam de chegar à musculatura. Assim, o músculo passa a utilizar a via anaeróbica para obtenção de energia. Nesse processo, há transformação de glicogênio em glicose, e como a glicólise é anaeróbica, há produção de lactato com queda do pH (ALVES; MANCIO, 2007).

A velocidade da queda do $\mathrm{pH}$, e o pH final da carne após 24 a 48 horas é muito variável. A queda do $\mathrm{pH}$ é mais rápida nos suínos, intermediária nos ovinos e mais lenta nos bovinos. Para bovinos, normalmente a glicólise se desenvolve lentamente e o $\mathrm{pH}$ inicial em torno de 7,0 cai para entre 6,4 e 6,8 após 5 horas e para entre 5,5 e 5,9 após 
24 horas. A adequada ocorrência do rigor mortis e a queda significativa do $\mathrm{pH}$ constituem características desejáveis da carne, pois o baixo $\mathrm{pH}$ inibe o crescimento bacteriano e a presença do ácido lático promove maciez, em virtude da conversão do colágeno em gelatina (ROÇA, 2001).

Durante o processo de rigor mortis podem ocorrer variações na taxa e extensão da queda natural do $\mathrm{pH}$ que irão influenciar na qualidade final da carne. Quando os bovinos são acometidos pelo estresse pré-abate, a reserva de glicogênio dos músculos desses animais pode ser parcial ou totalmente consumida. Conforme Pardi et al. (2001), a reserva de glicogênio muscular é passível de perdas ocasionadas pelo jejum, fadiga, exercícios exaustivos, medo, maus tratos ou pela suscetibilidade ao estresse. O medo, sobretudo os induzidos pelos maus tratos durante o transporte, recepção e condução nos frigoríficos, está entre causas mais relevantes de consumo de glicogênio de reserva.

Como consequência da redução brusca nas reservas deste composto, o estabelecimento do rigor mortis dar-se-á na primeira hora, pois a energia não será suficiente para sustentar o metabolismo anaeróbio e produzir ácido lático capaz de baixar gradativamente o pH a 5,5 durante as 24 horas após a morte. A carne resultante desse processo terá pH superior a 5,8, tornando-se mais escura e mais perecível uma vez que, na ausência de ácido lático e glicose livre, as bactérias utilizam os aminoácidos presentes na carne com produção de compostos de odores desagradáveis (LAWRIE, 2005).

A carne DFD (do inglês dark, firm and dry), caracterizada por ser escura, firme e seca, é um grave problema resultante de estresse crônico no período pré-abate responsável por exaurir as reservas de glicogênio, impedindo que $0 \mathrm{pH}$ decline adequadamente. A carne DFD é um problema do ponto de vista sanitário, pois a alta umidade e o pH elevado, próximo ao neutro, a torna mais susceptível à contaminação e ao desenvolvimento de microrganismos patógenos.

A ausência de glicose na superfície da carne DFD permite a microflora atacar e degradar os aminoácidos de forma primordial, dando lugar a compostos de odor intenso no processo de deterioração. As carnes DFD são mais suscetíveis a alterações microbianas não só no estado fresco, mas também durante processos de cura e é recomendado que seu consumo seja realizado o mais rápido possível (ROÇA, 2001).

Portanto, as explanações supracitadas, reforçam que a ausência de bem-estar no período que antecede o abate pode levar à produção de uma carne de qualidade inferior, o que resulta em decréscimo de produção e de vendas, ou origina produto de baixa qualidade (ALVES et al., 2016; SORNAS et al., 2016).

\section{CONSIDERAÇÕES FINAIS}

A cadeia da bovinocultura no Brasil vem avançando verticalmente e ajustando seus elos às novas demandas do mercado consumidor, todavia, o caminho a ser percorrido para que se alcance níveis adequados ainda é longo.

O manejo pré-abate, por ser uma condição estressante para o animal, pode aumentar a mortalidade animal, comprometer a qualidade de carne e, consequentemente, rentabilidade do sistema. Dessa forma, esta etapa requer estratégias coerentes e planejamento adequado, exercidos por um grupo de 
manejadores capacitados e comprometidos com a eficiência do processo. O sucesso do manejo pré-abate depende, sinergicamente, da competência e eficiência entre produtores, transportadores e o agroindústria.

\section{REFERÊNCIAS}

ALMEIDA, T.J.O.; SILVA, S.C.G.; TORRES, M.B.A.M.; FRANQUE, M.P. Lesões macroscópicas e causas de condenação de carcaças e vísceras de bovinos abatidos na microrregião de Garanhuns, Pernambuco, Brasil. Medicina Veterinária (UFRPE), Recife, v.11, n.4, p.292-300, $2017 . \quad$ Disponível: <http://www.journals.ufrpe.br/index.php/medicinaveterinaria/article/view/1959>. doi: 10.26605/medvet-n4-1959.

ALVES, A.R.; FIGUEIREDO JÚNIOR, J.P.; SANTANA, M.H.M. ANDRADE, M.V.M.; LIMA, J.B.A.; et al. Efeito do estresse sobre a qualidade de produtos de origem animal. PUBVET, Maringá, v.10, n.6, p.448-459, 2016. Disponível: http://www.pubvet.com.br/uploads/17239aaa6d339165f402ba5f0d4f84de.pdf.

ALVES, D.D.; MANCIO, A.B. Maciez da carne bovina - Uma revisão. Revista da FZVA, Uruguaiana, v.14, n.1, p. 193-216, $2007 . \quad$ Disponível: http://revistaseletronicas.pucrs.br/ojs/index.php/fzva/article/view/2488.

BARBUT, S. Review: Automation and meat quality-global challenges. Meat Science, v.96, p.335-345, $2014 . \quad$ Disponível: sciencedirect.com/science/article/abs/pii/S0309174013003100 doi.org/10.1016/j.meatsci.2013.07.002.

doi:

BROOM, D.M. The effects of land transport on animal welfare. Revue Scientifique et Technique, v.24, p.683-691, $2005 . \quad$ Disponível: https://pdfs.semanticscholar.org/a9aa/e2b901be80b5a25215815905a7f88a87b961.pdf.

CIVEIRA, M.P.; RENNER, R.M; VARGAS, R.E.S.; RODRIGUES, C.N. Avaliação do bem-estar animal em bovinos abatidos para consumo em frigorífico do Rio Grande do Sul. Revista Veterinária Foco, v.4, p.5-11, 2006. Disponível: http://www.scielo.br/scielo.php?script=sci_nlinks\&ref=000095\&pid=S1809$6891201300020000600013 \&$ Ing $=p t$

CNT - Confederação Nacional do Transporte. Pesquisa CNT de Rodovias 2018. Disponível em: <http://www.cnt.org.br>. Acesso em: 01 de setembro. 2018.

COUTINHO, M.A.S.; RAMOS, P.M.; SILVA, S.L.; MARTELLO, L.S.; PEREIRA, A.S.C.; et al. Divergent temperaments are associated with beef tenderness and the inhibitory activity of calpastatin. Meat Science. v.134, p.61-67, 2017. Disponível: www.ncbi.nlm.nih.gov/pubmed/28759886. doi: 10.1016 / j.meatsci.2017.06.017. 
CRUZ-MONTERROSA, R.G.; RESÉNDIZ-CRUZ, V.; RAYAS-AMOR, A.A.; LÓPEZ, M.; MIRANDA-DE LA LAMA, G.C. Bruises in beef cattle at slaughter in Mexico: Implications on quality, safety and shelf life of the meat. Tropical Animal Health and Production, v.49, p.145-152, 2017. Disponível: https://link.springer.com/article/10.1007/s11250-0161173-8. doi: doi.org/10.1007/s11250-016-1173-8

DINIZ, P.P.; SILVA, B.L.; PEREIRA, V.V.; GRANDE, P.A. Efeitos do transporte no bemestar e qualidade da carne de bovinos. BioEng, Tupã, v.5 n.3, p.137-141, 2011. Disponível: seer.tupa.unesp.br/index.php/BIOENG/article/download/122/121.

FONSECA, A.A.; TOMÉ, V.L.; PATACHI, A.M.; ZANINE, A.M.; NEGRÃO, F.M.; FEIJÓ, L.C. Efeito do transporte na qualidade e rendimento da carne. Pubvet. v.8 n.5 p.444586, 2014. Disponível: http://www.pubvet.com.br/artigo/1123/efeito-do-transporte-naqualidade-e-rendimento-da-carne.

FRASÃO, B.S.; NASCIMENTO, M.R.B.; COSTA, H.C.O.; MORAIS, H.R.; CARRIJO, K.F.; et al. Quantidade, Le descrição de contusões em Bovinos Abatidos sob Inspeção Sanitária. Acta Scientiae Veterinariae, v.42, p.1186-1192, 2014. Disponível: https://www.researchgate.net/publication/267269920_Quantity_Location_and_Descriptio n_of_Bruises_in_Beef_Cattle_Slaughtered_under_Sanitary_Inspection.

GOMIDE, L.A.M; RAMOS, E.M.; FONTES, P.R. Tecnologia de abate e tipificação de carcaças. 1 ed. Viçosa, 95p, 2006.

GOMIDE, L.A.M; RAMOS, E.M.; FONTES, P.R. Tecnologia de abate e tipificação de carcaças. 2 ed. Viçosa, 336p, 2014.

GONÇALVES, G.A.; SALOTTI-SOUZA, B.M. A importância do abate humanitário e bem-estar. Revista Científica de Medicina Veterinária-UNORP, v.1, n.1, p.40-55, 2017.

http://sivap.unorp.br:8083/ojs/index.php/revmedvetunorp/article/view/8/9.

GONZÁLEZ, L.A.; SCHWARTZKOPF-GENSWEIN, K.S.; BRYAN, M.; SILASI, R.; BROWN, F. Factors affecting body weight loss during commercial long haul transport of cattle in North America. Journal Animal Science, v.90, p.3630-3639, 2012. Disponível: www.ncbi.nlm.nih.gov/pubmed/22665642. doi: 10.2527 / jas.2011-4786.

GRANDIN, T. Animal welfare and society concerns finding the missing link. Meat Science, n.98, p.461-469, $2014 . \quad$ Disponível: https://www.sciencedirect.com/science/article/pii/S0309174014001314. doi: doi.org/10.1016/j.meatsci.2014.05.011

GUERRERO, A., VALERO, M.V.; CAMPO, M.M.; SAÑUDO, C. Some factors that affect ruminant meat quality: from the farm to the fork. Review. Acta Scientiarum. Animal Sciences, $\quad$ v.35, p.335-347, $2013 . \quad$ Disponível: 
http://www.scielo.br/scielo.php?script=sci_arttext\&pid=S1807-86722013000400001. doi: http://dx.doi.org/10.4025/actascianimsci.v35i4.21756.

LAWRIE, R.A. Ciência da carne. 6.ed. Porto Alegre: Artmed, 2005. 384p.

LEITE, C.R.; NASCIMENTO, M.R.B.; SANTANA, D.O.; GUIMARÃES, E.C.; MORAIS, H.R. Influência do manejo pré-abate de bovinos na indústria sobre os parâmetros de bem-estar animal e impactos no ph 24 horas post mortem. Biosci. J., Uberlândia, v.31, n.1, p.194-203, 2015.2 Disponível: www.seer.ufu.br/index.php/biosciencejournal/article/view/21879 doi: doi.org/10.14393/BJ-v31n1a2015-21879.

LUDTKE, C.B.; CIOCCA, J.R.P.; BARBALHO, P.C.; DANDIM, T.; VILELA, J.A.; FERRARINI, C. Abate humanitários de bovinos. World Animal Protection. São Paulo, 2015, 136p.

MELO, A.F.; MOREIRA, J.M.; ATAIDES, D.A.; GUIMARÃES, A.M.; LOIOLA, J.L.; OLIVEIRA, R.Q. Fatores que influenciam na qualidade da carne bovina: Revisão. PUBVET. $\quad$ v.10, n.10, p.785-794, $2016 . \quad$ Disponível: www.pubvet.com.br/uploads/34faf0194c8d64cb5ea9b8103824ed77.pdf doi: 10.22256/pubvet.v10n10.785-794.

MENDONÇA, F.S.; VAZ, R.Z.; COSTA, O.A.D.; GONÇALVES, G.V.B.; MOREIRA, S.M. Fatores que afetam o bem-estar de bovinos durante o período pré-abate. Archivos Zootecnia, Córdoba. v.65, p.279-287, $2016 . \quad$ Disponível: https://dialnet.unirioja.es/descarga/articulo/6505166.pdf.

MENDONÇA, F.S.; VAZ, R.Z.; VAZ, F.N.; RESTLE, J. Breed and carcass characteristics on losses by bruises and meat ph in beef of steers and culling cows. Ciência Animal Brasileira, v.18, p.1-10, 2017. Disponível: http://www.scielo.br/pdf/cab/v18/1809-6891cab-18-e45295.pdf. doi: 10.1590/1089-6891v18e-45295.

MENDONÇA, F.S.; VAZ, R.V.; VAZ, F.N.; LEAL, W.S.; SILVEIRA, I.D.B.; RESTLE, J.; BOLIGON, A.A.; CARDOSO, F.F. Causes of bruising in carcasses of beef cattle during farm, transport, and slaughterhouse handling in Brazil. Animal Science Journal, v. 90, p.288-296, 2019. Disponível: /onlinelibrary.wiley.com/doi/epdf/10.1111/asj.13151. doi: https://doi.org/10.1111/asj.13151.

Miranda-de La Lama, G.; Leyva, I.G.; Barreras-Serrano, A.; Pérezlinares, C.; SánchezLópez, E.; et al. Assesment of cattle welfare at a comercial slaugther plant in the northwest of Mexico. Tropical Animal Health Production, v.44, p.497-504, 2012. Disponível: www.ncbi.nlm.nih.gov/pubmed/21789548. doi: 10.1007 / s11250-011-9925y. 
MPAKAMA, T.; CHULAYO, A.Y.; MUCHENJE, V. Bruising in slaughter cattle and its relationship with creatine kinase levels and beef quality as affected by animal related factors. Asian-Australasian Journal of Animal Science, v.27, p.717-725. 2014. Disponível: www.ncbi.nlm.nih.gov/pmc/articles/PMC4093197/ doi:doi.org/10.5713/ajas.2013.13483

MOREIRA, P.S.A.; POLIZEL NETO, A.; MARTINS, L.R.; LOURENÇO, F.J.; PALHARI, C.; et al. Ocorrência de hematomas em carcaças de bovinos transportados por duas distâncias. Revista Brasileira de Saúde e Produção Animal, v.15, n.3, p.689-695, 2014. doi: dx.doi.org/10.1590/S1519-99402014000300018.

MOREIRA, S.; MENDONÇA, F.S.; COSTA, P.T.; DE CONTO, L.; CORRÊA, G.F.; et al. Carne bovina: Percepções do consumidor frente ao bem-estar animal - Revisão de literatura. REDVET Revista Eletrônica de Veterinária, v.18, n.5 p. 1-17, 2017. Disponível: http://www.veterinaria.org/revistas/redvet/n050517/051708.pdf.

NUNES, C.L.C.; OLIVEIRA, D.M.; BACHES, B.; ESCOBAR, L.S.; PIAZZON, C.J.; et al. Ocorrência de hematomas e lesões em carcaças bovinas e sua relação com o transporte rodoviário. Boletim da Indústria Animal, v.75, p.1-7, 2018. Disponível: http://www.iz.sp.gov.br/bia/index.php/bia/article/view/1487/1438.

doi: doi.org/10.17523/bia.2018.v75.e1434.

OIE (Office International des Epizooties). World Organization for Animal Health.Terrestrial Animal Health Code. Guidelines for the transport of animals by land, 2014. Disponível: https://www.oie.int/doc/ged/D10905.PDF.

PARANHOS DA COSTA, M.J.R. Ambiência na produção de bovinos de corte a pasto. Anais de Etologia, n.18, p.26-42, 2000.

PARANHOS DA COSTA, M.J.R.; QUINTILIANO, M.H.; TSEIMAZIDES, S.P. Boas práticas de manejo - transporte. Jaboticabal: FUNEP, 2010. Disponível: <http://www.pfizersaudeanimal.com.br/PDFs/Transporte.PDF>. Acesso em: 04 dez. 2018.

PARANHOS DA COSTA, M.J.R.; HUERTAS, S.; GALLO, C.; DALLA COSTA, O.S. Strategies to promote farm animal welfare in Latin America and their effects on carcass and meat quality traits. Meat Science, v.92, n.3, p.221-226, 2012. Disponível: www.sciencedirect.com/science/article/abs/pii/S0309174012000861. doi: doi.org/10.1016/j.meatsci.2012.03.005.

PARDI, M.C.; SANTOS, F.I.; SOUZA, E.R.; PARDI, H.S. Ciência, higiene e tecnologia da carne. Goiânia: CEGRAF-UFG, v.2, p.45-65, 2001.

PEIXOTO, M.G.C.D.; PIRES, M.F.A.; PEREIRA, M.C.; CARVALHO, M.R.S.; RIBEIRO, G.C.; et al. Integrando o temperamento às características de importância para o 
melhoramento de bovinos de leite: resultados de um estudo com fêmeas Guzerá. Revista Brasileira de Zootecnia, v.40, p.26-37, 2011. Disponível: http://www.sbz.org.br/revista/artigos/66255.pdf.

PELLECCHIA, A.J.R. Caracterização do risco de hematomas em carcaças bovinas Dissertação (mestrado) - Universidade Estadual Paulista, Faculdade de Ciências Agrárias e Veterinárias - Jaboticabal, 78p., 2014.

PETRONI, R.; BÜRGER, K.P.; GONÇALEZ, P.O. Ocorrência de contusões em carcaças bovinas em frigorífico. Revista Brasileira de Saúde e Produção Animal, Salvador, v.14, n.3, p.478-484, 2013. Disponível: http://dx.doi.org/10.1590/S151999402013000300009 .

POLIZEL NETO, A.; ZANCO, N., LOLATTO, D.C.J.; MOREIRA, P.S.A.; DROMBOSKI, $\mathrm{T}$. Perdas econômicas ocasionadas por lesões em carcaças de bovinos abatidos em matadouro-frigorífico do norte de Mato Grosso. Pesquisa Veterinária Brasileira v.35, n.4, p.324-328, 2015. Disponível: http://www.scielo.br/pdf/pvb/v35n4/0100-736X-pvb-3504-00324.pdf. doi: 10.1590/S0100-736X2015000400002.

ROÇA, R.O. Abate humanitário: manejo ante-mortem. Revista TecCarnes, v.3, p.7-12. 2001.

ROMERO M.H.; URIBE-VELÁSQUEZ, L.F.; SÁNCHEZ, J.A.; MIRANDA LA LAMA, M.G.C. Risk factors influencing bruising and high muscle $\mathrm{pH}$ in Colombian cattle carcasses due to transport and pre-slaughter operations. Meat Science, v.95, p.256263. 2013. Disponível: sciencedirect.com/science/article/abs/pii/S0309174013002088 doi: doi.org/10.1016/j.meatsci.2013.05.014.

SORNAS, A.S.; ROSSI JÚNIOR, P.; MOIZES, F.F. Perdas ocasionadas por lesões em carcaças bovinas e seu reflexo econômico no estado do Paraná. Archives of Veterinary Science, v.21, n.3, p.119-130, 2016. Disponível: revistas.ufpr.br/veterinary/article/view/45372/29608. doi:

http://dx.doi.org/10.5380/avs.v21i3.45372

SILVA, A.A.; BORGES, L.F.K. Considerações sobre o bem-estar animal na produção de bovinos - revisão bibliográfica. Ciência e Tecnologia, v.1, n.1, p.1-8. 2015. Disponível: http://revistaeletronica.unicruz.edu.br/index.php/CIENCIAETECNOLOGIA/article/view/47 1.

SILVA, J.L.; BERTOLONI, W.; RIBEIRO, J.S.A. Indicadores de estresse e qualidade de carne de bovinos transportados em diferentes tipos de caminhões (tradicional, carreta de um piso e carreta de dois pisos) e diferentes distâncias na região de Cuiabá/ MT/ Brasil. Archives of Veterinary Science. v.21, n.3, p.68-76, 2016. Disponível: revistas.ufpr.br/veterinary/article/view/38234/29609. 
STRAPPINI, A.C.; METZ, J.H.M.; GALLO, C.B.; KEMP, B. Origin and assessment of bruises at slaughter. Journal of Animal Science, v.3, p.728-736, 2009. Disponível: www.ncbi.nlm.nih.gov/pubmed/22444452. doi: 10.1017 / S1751731109004091.

STRAPPINI, A.C.; METZ, J.H.M.; GALLO, C.; FRANKENA, K. VARGAS, R.; et al. Bruises in culled cows: when, where and how are they inflicted?. Animal, v.7, n.3, p.485-491. 2013. Disponível: www.ncbi.nlm.nih.gov/pubmed/23046510. doi: 10.1017 / S1751731112001863. 